\title{
PENGARUH ESCAPE GAP PADA ALAT TANGKAP BUBU LIPAT TERHADAP HASIL TANGKAPAN RAJUNGAN (PORTUNUS PELAGICUS)
}

\author{
Shofiatul Kholishoh ${ }^{a}$, Muhammad Arif Rahman ${ }^{\text {b, }}$, Dewa Gede Raka Wiadnya \\ ${ }^{\text {a}}$ Pemanfaatan Sumberdaya Perikanan, Fakultas Perikanan dan Ilmu Kelautan, Universitas Brawijaya \\ ${ }^{\mathrm{b}}$ RG MEXMA, Fakultas Perikanan dan Ilmu Kelautan, Universitas Brawijaya \\ ${ }^{\mathrm{c}}$ RG Ichthyo-Fauna, Fakultas Perikanan dan Ilmu Kelautan, Universitas Brawijaya \\ *Koresponden penulis : arifelzain@ub.ac.id
}

\begin{abstract}
Abstrak
Rajungan (Portunus pelagicus) merupakan komoditas ekonomis penting ke-4 yang telah dieskpor ke berbagai negara. Berdasarkan Permen KP No. 56 tahun 2016, rajungan hanya boleh ditangkap dengan ukuran lebar karapas $>10 \mathrm{~cm}$ atau berat $>60 \mathrm{~g}$ ekor $^{-1}$. Penelitian ini bertujuan untuk mengetahui pengaruh bubu dengan escape gap terhadap ukuran hasil tangkapan rajungan berdasarkan experimental fishing. Percobaan lapang dilakukan pada bulan Januari - Februari 2019 di Desa Pangkahwetan, Kabupaten Gresik. Analisis data yang digunakan adalah regresi linier dan uji korelasi. Hasil analisis data didapatkan dimensi escape gap yang sesuai adalah 4,6*2,6 $(\mathrm{p} * \mathrm{t}) \mathrm{cm}$. Hasil tangkapan dengan lebar karapas $\leq 10 \mathrm{~cm}$ pada bubu dengan escape gap lebih sedikit dari pada bubu tanpa escape gap (8\% : 29\%). Pada uji korelasi didapatkan nilai signifikansi sebesar $0,113>0,05$ sehingga terima H0, tidak ada pengaruh penggunaan escape gap pada bubu lipat terhadap lebar karapas hasil tangkapan rajungan (Portunus pelagicus). Bubu dengan escape gap memiliki rata - rata berat yang lebih besar dari pada bubu tanpa escape gap (115,9 : 87,4). Pada uji korelasi didapatkan nilai signifikansi sebesar 0,056 > 0,05 sehingga terima H0, penggunaan escape gap pada bubu lipat tidak berpengaruh nyata terhadap berat hasil tangkapan rajungan. Penelitian ini dimungkinan bisa memberikan hasil lebih nyata jika ulangan diperbanyak.
\end{abstract}

Kata kunci: Sompeh, Escape Vent, Celah Pelolosan, Permen KP No. 56 tahun 2016

\begin{abstract}
Blue Swimming Crab, Portunus pelagicus (BSC) is the fourth important economic commodity that has been exported to various countries. Based on regulations of Marine and Fisheries Ministries No. 56 of 2016, BSCs may only be caught with a size of carapace width $>10 \mathrm{~cm}$ or weight $>60 \mathrm{~g}$ head ${ }^{-1}$. This study aims to determine the effect of trap with the escape gap on the size of the BSC catch based on experimental fishing. The field experiment was conducted in January - February 2019 in Pangkahwetan Village, Gresik Regency. The data analysis used are linear regression and correlation test. The results of data analysis obtained an optimal escape gap dimension at $4.6 * 2.6(l * h) \mathrm{cm}$. The catch with a carapace width of $\leq 10 \mathrm{~cm}$ in trap with an escape gap is less than the trap without an escape gap (8\%:29\%). The correlation test shows signifficant value 0,113>0,05, accept $\mathrm{HO}$, so that the use of the escape gap has no effect on the carapace width of the BSC catch. Trap with the escape gap has an average weight greater than the number without escape gap (115.9 : 87.4). The correlation test shows signifficant value 0,056 > 0,05, accept H0, so that the use of the escape gap has no effect on the weight of the BSC catch. This research is likely to provide more tangible results if replications are reproduced.
\end{abstract}

Keywords: Sompeh, Escape Vent, Escape Gap, Permen KP No. 56 tahun 2016

\section{PENDAHULUAN}

Rajungan (Portunus pelagicus)
merupakan salah satu anggota famili
Portunidae yang berkulit keras sehingga
pertumbuhannya dicirikan oleh proses ganti
kulit (moulting) [1]. Rajungan hidup di
perairan dangkal dan estuari yang bersubstrat

pasir, termasuk sekitar bakau, padang lamun dan ganggang. Rajungan biasanya ditemukan pada kedalaman $<1 \mathrm{~m}$ hingga $50 \mathrm{~m}$ di seluruh India dan Indo-Pasifik Barat [2].

Sebagai komoditas ekonomis penting, rajungan memiliki peringkat nilai ekspor ke-4 di Indonesia [3]. Permintaan pasar yang tinggi seiring dengan harga yang menguntungkan, 
telah menyebabkan eksploitasi yang intensif terhadap sumberdaya rajungan di Indonesia, ditambah lagi dengan produksi rajungan yang masih mengandalkan alam (wild catch) menyebabkan sumberdaya rajungan semakin terancam. Pangsa pasar rajungan yang dominan adalah ekspor dalam bentuk daging yang dikalengkan [4] dengan negara tujuan ekspor antara lain Jepang, Singapura, dan Amerika [5].

Dalam rangka menjaga keberadaan dan ketersediaan stok rajungan, Menteri Kelautan dan Perikanan telah menetapkan peraturan penangkapan dan/atau pengeluaran rajungan dari wilayah Republik Indonesia [6]. Penangkapan dan/atau pengeluaran rajungan (Portunus spp.) dari wilayah Negara Republik Indonesia hanya dapat dilakukan dalam kondisi tidak bertelur dan memiliki ukuran lebar karapas $>10 \mathrm{~cm}$ atau berat $>60 \mathrm{~g} \mathrm{ekor}^{-1}$ [7].

Rajungan pada umumnya ditangkap dengan menggunakan alat tangkap bubu (traps). Alat ini bersifat pasif, yakni memerangkap ikan untuk masuk ke dalamnya namun sulit untuk meloloskan diri [8]. Berdasarkan metode penangkapan tersebut, bubu dimungkinkan akan menangkap rajungan yang memiliki lebar karapas $\leq 10$ $\mathrm{cm}$. Menurut Ummaiyah, et al. (2017), ukuran mata jaring pada bubu yang relatif kecil maka ikan - ikan kecil memiliki peluang yang besar untuk tertangkap pada bubu dan tidak dapat meloloskan diri [9]. Hal ini dibuktikan dengan penelitian yang dilakukan oleh Nugraheni, et al. (2015) di Kabupaten Pati, hasil tangkapan yang didapatkan di zona 1 memiliki kelas ukuran lebar karapas 60 - 138 mm sedangkan pada zona 2 memiliki kelas ukuran lebar karapas $92-168 \mathrm{~mm}[10]$.

Oleh karena itu, diperlukan bubu lipat yang mampu meloloskan rajungan dengan lebar karapas $\leq 10 \mathrm{~cm}$ melalui penambahan celah pelolosan (escape gap) dengan letak, bentuk dan dimensi tertentu [11]. Berdasarkan uraian diatas, penelitian ini bertujuan untuk mengetahui hubungan panjang, lebar karapas dan tinggi tubuh rajungan untuk mengetahui dimensi escape gap yang sesuai; membuat desain escape gap pada bubu lipat serta mengetahui perbedaan hasil tangkapan rajungan pada bubu tanpa escape gap dan bubu dengan escape gap berdasarkan experimental fishing.

\section{METODE}

\section{Pengambilan Data}

Penelitian ini dilaksanakan selama bulan Januari - Februari 2019 di Desa Pangkahwetan, Kecamatan Ujung Pangkah, Kabupaten Gresik. Pengambilan data dilakukan dengan experimental fishing, yaitu uji teknologi baru atau modifikasi untuk penangkapan ikan guna perikanan berkelanjutan.

Experimental fishing dilakukan dengan menggunakan 5 buah bubu tanpa escape gap milik nelayan dan 5 buah bubu dengan escape gap hasil modifikasi yang disusun dalam urutan silang dengan jarak antarbubu adalah $10 \mathrm{~m}$ (Gambar 1). Pengulangan dilakukan sebanyak lima kali dalam lima trip dimana setiap trip dilakukan dalam satu hari. Data yang diambil adalah ukuran lebar karapas (diukur menggunakan jangka sorong dengan ketelitian $0,1 \mathrm{~mm}$ ) dan berat rajungan (diukur menggunakan timbangan digital dengan ketelitian $1 \mathrm{~g}$ ). Hasil tangkapan kedua jenis bubu tersebut akan dianalisis untuk mengetahui perbedaan hasil tangkapannya.

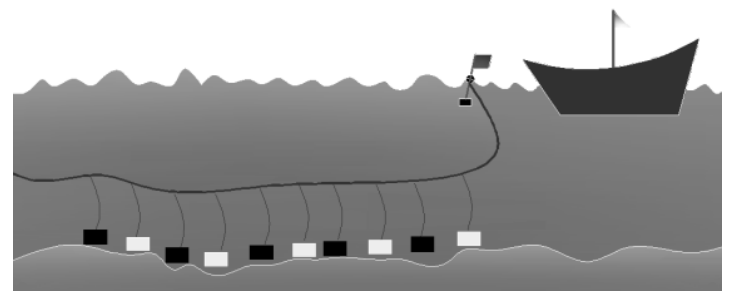

Gambar 1. Ilustrasi penyusunan bubu (bubu terang: bubu dengan escape gap, bubu gelap: bubu tanpa escape gap)

\section{Metode Analisis Data}

Analisis yang digunakan dalam mengamati hubungan panjang, lebar karapas dan tinggi tubuh rajungan adalah metode regresi linier. Regresi linier adalah sebuah metode yang digunakan untuk mengetahui hubungan dari dua atau lebih variabel. Dalam 
metode ini, akan dibedakan dua jenis variabel yaitu variabel bebas dan variabel respon. Variabel yang mudah didapat atau tersedia digolongkan kedalam variabel bebas sedangkan variabel yang terjadi karena variabel bebas disebut variabel respon. Untuk keperluan analisis, variabel bebas akan dinyataan dengan $X_{1}, X_{2}, X_{3}, \ldots X_{k}(K \geq 1)$, sedangkan variabel respon akan dinyatakan dengan Y. Persamaan regresi linier sederhana adalah $\mathrm{Y}=\mathrm{a}+\mathrm{b} * \mathrm{X}$. Regresi dengan $\mathrm{X}$ merupakan variabel bebasnya dan $\mathrm{Y}$ variabel responnya dinamakan regresi $Y$ atas $X$ [12].

Pada penelitian ini, data hasil pengukuran panjang, lebar karapas dan tinggi tubuh rajungan dianalisis untuk menentukan panjang karapas dan tinggi tubuh rajungan ketika lebar karapas $=10 \mathrm{~cm}$. Hal ini didasarkan pada Permen KP nomor 56 tahun 2016, sehingga didapatkan dimensi yang sesuai untuk escape gap. Adapun hipotesis pada analisis hubungan panjang dan lebar karapas Portunus pelagicus adalah:

- H0 : tidak ada hubungan antara panjang dan lebar karapas rajungan (Portunus pelagicus).

- H1: ada hubungan antara panjang dan lebar karapas rajungan (Portunus pelagicus).

Sedangkan hipotesis pada analisis hubungan tinggi tubuh dan lebar karapas Portunus pelagicus adalah:

- H0 : tidak ada hubungan antara tinggi tubuh dan lebar karapas rajungan (Portunus pelagicus).

- H1: ada hubungan antara tinggi tubuh dan lebar karapas rajungan (Portunus pelagicus).

Analisis yang digunakan dalam mengamati hasil tangkapan pada experimental fishing adalah uji korelasi. Uji korelasi bertujuan untuk menentukan ada tidaknya pengaruh escape gap pada bubu lipat terhadap lebar karapas dan berat hasil tangkapan rajungan. Hipotesis pada analisis pengaruh escape gap terhadap lebar karapas hasil tangkapan rajungan (Portunus pelagicus) adalah:

H0 : tidak ada pengaruh escape gap pada bubu lipat terhadap lebar karapas hasil tangkapan rajungan (Portunus pelagicus).
H1 : ada pengaruh escape gap pada bubu lipat terhadap terhadap lebar karapas hasil tangkapan rajungan (Portunus pelagicus).

Sedangkan hipotesis pada analisis pengaruh escape gap terhadap berat hasil tangkapan rajungan (Portunus pelagicus) adalah:

$\mathrm{H} 0$ : tidak ada pengaruh escape gap pada bubu lipat terhadap berat hasil tangkapan rajungan (Portunus pelagicus).

H1 : ada pengaruh escape gap pada bubu lipat terhadap terhadap berat hasil tangkapan rajungan (Portunus pelagicus).

\section{HASIL DAN PEMBAHASAN}

\section{Analisis Hubungan Panjang, Lebar Karapas dan Tinggi Tubuh Rajungan}

Data yang digunakan dalam analisis ini adalah data pengukuran morfologi rajungan dengan jumlah sampel sebanyak 1842 ekor. Rata - rata rajungan pada sampel tersebut memiliki lebar karapas $10,4 \mathrm{~cm}$, berat $83 \mathrm{~g}$, panjang karapas $4,7 \mathrm{~cm}$ dan tinggi $2,7 \mathrm{~cm}$. Berdasarkan Permen KP nomor 56 tahun 2016, diperlukan dimensi pada escape gap dengan tujuan meloloskan rajungan yang memiliki ukuran lebar karapas $\leq 10 \mathrm{~cm}$. Hal ini sesuai dengan lebar karapas rajungan ketika pertama kali matang gonad. Ukuran lebar karapas ketika matang gonad pada betina diestimasikan sebesar 9,6 cm [13]. Pentingnya menangkap sumberdaya rajungan yang telah matang gonad akan sangat mendukung keberlanjutan stoknya di alam.

Analisis hubungan lebar dan panjang karapas menghasilkan nilai a (intercept) sebesar 0,2292 dan b (slope) sebesar 0,4326 sehingga persamaan yang didapatkan adalah $\mathrm{Y}=0,2292+0,4326 \mathrm{X}$ atau Panjang $=0,2292$ $+0,4326 *$ Lebar dengan nilai $\mathrm{R}^{2}=0,8278$ artinya hubungan panjang dan lebar karapas bersifat linier positif yang kuat (Gambar 2) dengan keeratan antarvariabel sebesar $83 \%$, semakin bertambah nilai lebar karapas maka semakin bertambah pula nilai panjang karapas. Sehingga keputusan yang dapat diambil adalah tolak $\mathrm{H} 0$ dan terima $\mathrm{H} 1$, 
terdapat hubungan antara panjang dan lebar karapas rajungan (Portunus pelagicus).

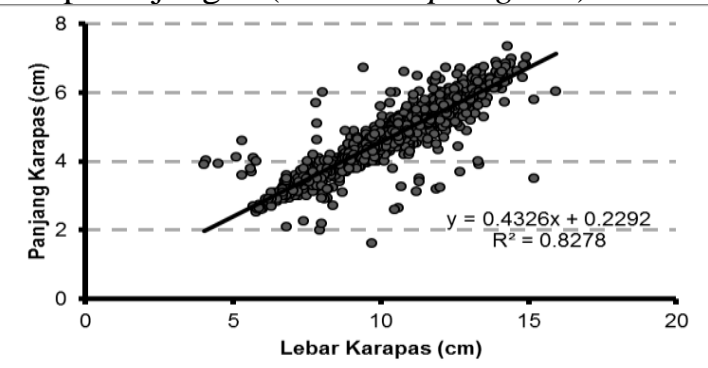

Gambar 2. Hubungan panjang dan lebar karapas

Analisis hubungan lebar karapas dan tinggi tubuh rajungan menghasilkan nilai a (intercept) sebesar 0,184 dan b (slope) sebesar 0,2412 sehingga persamaan yang didapatkan adalah $\mathrm{Y}=0,184+0,2412 \mathrm{X}$ atau Tinggi $=$ $0,184+0,2412 *$ Lebar dengan nilai $\mathrm{R}^{2}=$ 0,6488 artinya hubungan lebar karapas dan tinggi tubuh bersifat linier positif yang sedang (Gambar 3) dengan keeratan antarvariabel sebesar $65 \%$, semakin bertambah nilai lebar karapas maka semakin bertambah pula nilai tinggi tubuh rajungan. Sehingga keputusan yang dapat diambil adalah tolak H0 dan terima $\mathrm{H} 1$, terdapat hubungan antara tinggi tubuh dan lebar karapas rajungan (Portunus pelagicus).

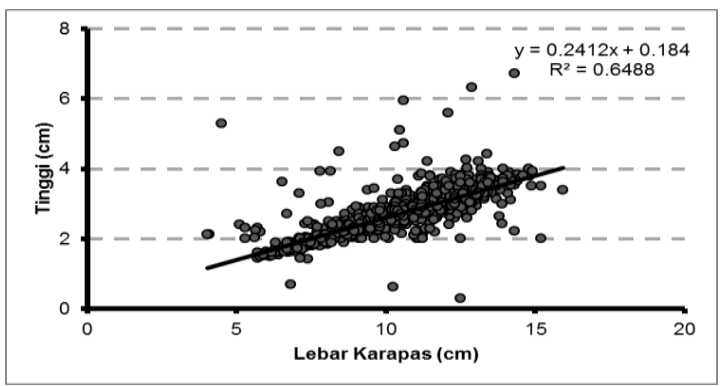

Gambar 3. Hubungan tinggi tubuh dan lebar karapas

Hasil analisis ini sebanding dengan penelitian hubungan antar ukuran tubuh rajungan di Perairan Utara Lamongan Jawa Timur yang menunjukkan bahwa secara signifikan terdapat hubungan linier positif antara panjang dan lebar karapas rajungan serta antara tinggi dan lebar karapas [14].

\section{Pembuatan Desain Escape Gap pada Alat Tangkap Bubu Lipat}

Tingkah laku rajungan yang berjalan miring [15] sehingga dimensi escape gap didasarkan pada panjang karapas. Berdasarkan hubungan linier antara panjang dan lebar karapas (Gambar 2) didapatkan panjang ketika lebar karapas $=10 \mathrm{~cm}$ adalah $4,6 \mathrm{~cm}$. Sedangkan hubungan linier antara tinggi dan lebar karapas (Gambar 3) menghasilkan tinggi rajungan ketika lebar karapas $=10 \mathrm{~cm}$ adalah 2,6 cm. Berbeda dengan penelitian yang dilakukan oleh Kurniasih, et al. (2016), rajungan dengan lebar karapas dibawah $10 \mathrm{~cm}$ memiliki panjang karapas $5 \mathrm{~cm}$ dan tebal 2,1 $\mathrm{cm} \mathrm{[11].}$

Sementara itu, menurut Boutson, et al.(2009), letak escape gap yang paling banyak meloloskan rajungan adalah pada sisi bawah (lower side panel) bubu [16]. Escape gap didesain seefektif mungkin untuk hanya meloloskan rajungan dengan ukuran $\leq 10 \mathrm{~cm}$, sehingga desain escape gap memiliki dimensi $4,6 * 2,6 \mathrm{~cm}$ yang terletak di sisi bawah bubu (Gambar 4 dan Gambar 5).

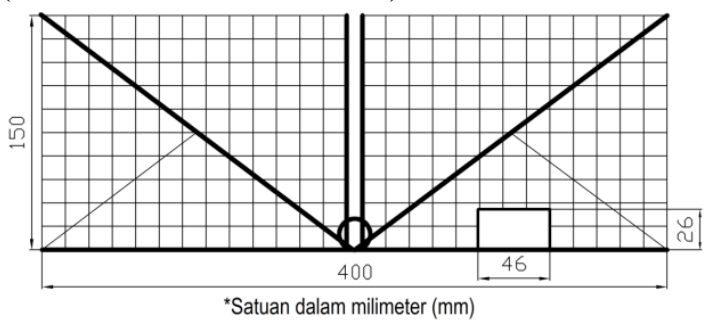

Gambar 4. Desain bubu dengan escape gap (tampak depan)

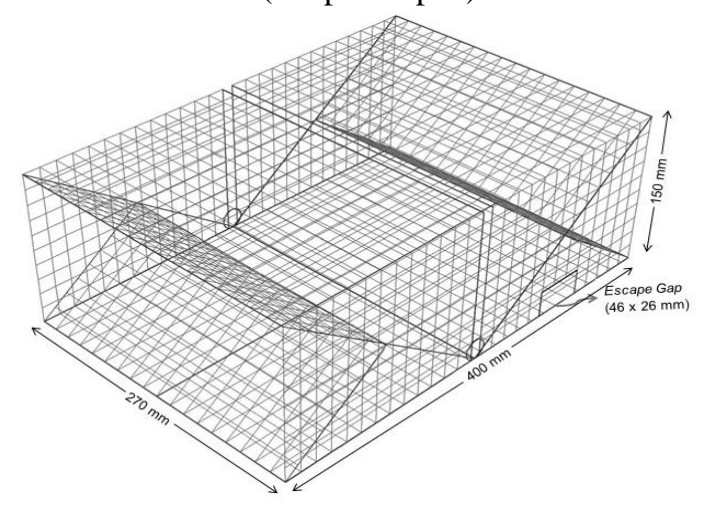

Gambar 5. Desain bubu dengan escape gap (tampak keseluruhan)

Bubu dengan escape gap dirancang untuk meloloskan rajungan dengan ukuran lebar karapas maksimal $10 \mathrm{~cm}$. Sehingga 
diharapkan seluruh hasil tangkapan rajungan dapat memenuhi standar peraturan yang ditetapkan oleh Kementerian Kelautan dan Perikanan (Permen KP No. 56 Tahun 2016).

\section{Experimental Fishing Bubu dengan Escape Gap}

Berdasarkan hasil penelitian, diperoleh spesies Portunus pelagicus sebanyak 21 ekor pada bubu tanpa escape gap dan 13 ekor pada bubu dengan escape gap. Sehingga persentase hasil tangkapan bubu tanpa escape gap sebesar $62 \%$ dan bubu dengan escape gap sebesar $38 \%$ (Gambar 6).

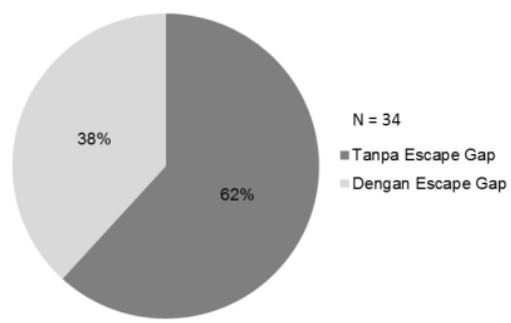

Gambar 6. Persentase hasil tangkapan berdasarkan jenis bubu

Pada bubu tanpa escape gap, sebaran lebar karapas (CW) diperoleh nilai minimum sebesar $8,7 \mathrm{~cm}$ dan nilai maksimum sebesar $13,4 \mathrm{~cm}$. Persebaran terkumpul pada kisaran 9 - $12 \mathrm{~cm}$. Jumlah rajungan dengan lebar karapas $\leq 10 \mathrm{~cm}$ adalah 6 ekor $(29 \%)$ dan rajungan dengan lebar karapas $>10 \mathrm{~cm}$ adalah 15 ekor (71\%) (Gambar 7).

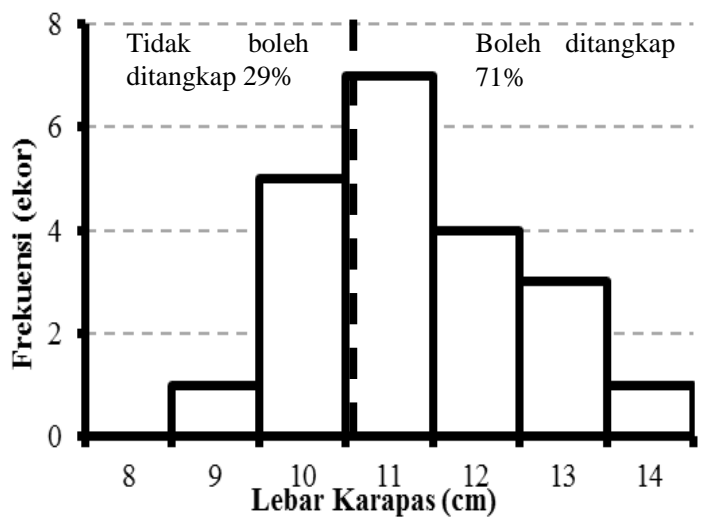

Gambar 7. Persentase frekuensi lebar karapas Portunus pelagicus dari bubu tanpa escape gap

Pada bubu dengan escape gap, sebaran lebar karapas $(\mathrm{CW})$ diperoleh nilai minimum sebesar 7,5 $\mathrm{cm}$ dan nilai maksimum sebesar $13,9 \mathrm{~cm}$. Persebaran terkumpul pada kisaran $10-13 \mathrm{~cm}$. Jumlah rajungan dengan lebar karapas $\leq 10 \mathrm{~cm}$ adalah 1 ekor $(8 \%)$ dan rajungan dengan lebar karapas $>10 \mathrm{~cm}$ adalah 12 ekor $(92 \%)$.

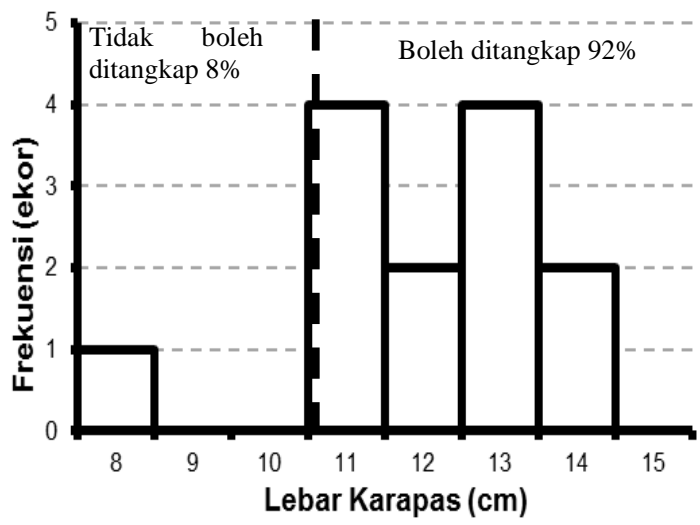

Gambar 8. Persentase frekuensi lebar karapas Portunus pelagicus dari bubu dengan escape gap

Berdasarkan analisis diatas dapat diketahui bahwa hasil tangkapan Portunus pelagicus pada bubu dengan escape gap baik yang berukuran $\leq 10 \mathrm{~cm}$ maupun secara keseluruhan jumlahnya lebih sedikit dibandingkan dengan bubu tanpa escape gap. Hal ini sesuai dengan penelitian Kurniasih. et al, (2016) di Teluk Banten, bubu tanpa celah pelolosan mendapatkan hasil tangkapan rajungan dengan lebar karapas $<10 \mathrm{~cm}$ sebanyak 13 ekor, sedangkan bubu yang memakai celah pelolosan hanya mendapatkan 6 ekor. Secara keseluruhan hasil tangkapan pada bubu tanpa celah pelolosan adalah 64 ekor sedangkan pada bubu dengan celah pelolosan adalah 46 ekor [11]. Berbeda dengan penelitian yang dilakukan oleh Ummaiyah. et al, (2017) di Perairan Kabupaten Rembang. Celah pelolosan yang digunakan dalam penelitian ini berukuran panjang $10 \mathrm{~cm}$ dan lebar $2 \mathrm{~cm}$ dengan 3 perlakuan yaitu bubu tanpa celah, bubu dengan 1 celah pelolosan dan bubu dengan 2 celah pelolosan. Hasil tangkapan rajungan (Portunus pelagicus) dengan lebar karapas $\leq$ $10 \mathrm{~cm}$ pada bubu tanpa celah pelolosan adalah sebanyak 42 ekor, bubu dengan 1 celah pelolosan sebanyak 56 ekor dan bubu dengan 2 celah pelolosan sebanyak 47 ekor [9]. Berbedanya hasil penelitian ini dengan 
penelitian sebelumnya dikarenakan perbedaan variabel dan ukuran escape gap yang digunakan.

Namun pada analisis uji korelasi didapatkan nilai sigifikansi sebesar 0,113 > 0,05 sehingga terima $\mathrm{H} 0$, tidak ada pengaruh penggunaan escape gap pada bubu lipat terhadap lebar karapas hasil tangkapan rajungan (Portunus pelagicus). Sesuai dengan penelitian yang dilakukan oleh Kurniasih. et $a l$, (2016), di Teluk Banten, dimana hasil uji anova menunjukkan bahwa $\mathrm{F}$ hitung lebih kecil dari $F$ tabel yaitu 1,308 $<3,12$ yang artinya penggunaan celah pelolosan tidak berpengaruh nyata terhadap jumlah total rajungan yang tertangkap [11]. Sebanding juga dengan penelitian yang dilakukan Prakosa. et al, (2017) di TPI Demaan Kabupaten Jepara Jawa Tengah. Pada analisis Levene's test didapatkan hasil Sig. yang diperoleh adalah 0,513 dan 0,518, menunjukkan nilai Sig. $>0,05$. Hal ini menunjukkan tidak ada perbedaan signifikan antara hasil tangkapan rajungan (Portunus pelagicus) pada bubu kubah tanpa celah pelolosan dan bubu kubah dengan celah pelolosan [15].

Total berat (W) rajungan yang diperoleh selama penelitian yaitu $3.343 \mathrm{~g}$ atau $3,4 \mathrm{~kg}$. Bubu tanpa escape gap memiliki total berat sebesar $1.836 \mathrm{~g}$ dengan rata - rata $87,4 \mathrm{~g}$. Bubu dengan escape gap memiliki total berat sebesar $1.507 \mathrm{~g}$ dengan rata -rata $115,9 \mathrm{~g}$ (Gambar 15). Pada uji korelasi didapatkan nilai sigifikansi sebesar $0,056>0,05$ sehingga terima $\mathrm{H} 0$, tidak ada pengaruh penggunaan escape gap pada bubu lipat tidak berpengaruh nyata terhadap berat hasil tangkapan rajungan (Portunus pelagicus). Penelitian ini sebanding dengan penelitian Kurniasih. et al, (2016) di Teluk Banten, bobot total rajungan yang diperoleh selama penelitian yaitu $15.556 \mathrm{~g}$. Perlakuan a (celah pelolosan terletak di tengah atas) memiliki jumlah bobot total tertinggi sebanyak $6.116 \mathrm{~g}$, perlakuan b (celah pelolosan terletak di atas funnel) $4.314 \mathrm{~g}$ dan perlakuan $\mathrm{c}$ (celah pelolosan terletak di samping bawah) sebanyak 5.126 g. Hasil anova total bobot rajungan menunjukkan bahwa $\mathrm{F}$ hitung $<\mathrm{F}$ tabel $(1,317<3,12)$ yang berarti bahwa penggunaan celah pelolosan tidak berpengaruh nyata terhadap total bobot rajungan yang ditangkap selama penelitian [11].

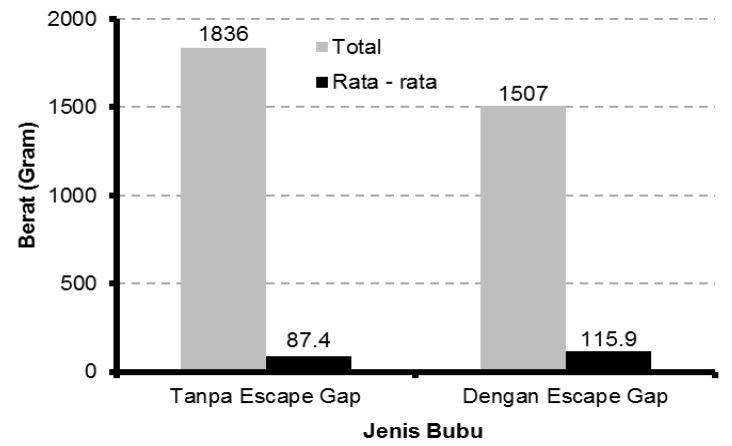

Gambar 9. Berat hasil tangkapan Portunus pelagicus berdasarkan jenis bubu

Secara deskriptif, bubu lipat dengan escape gap telah mampu mengurangi jumlah hasil tangkapan Portunus pelagicus dengan lebar karapas $\leq 10 \mathrm{~cm}$ meskipun masih ditemukan hasil tangkapan dengan ukuran tersebut. Hal ini dimungkinkan bahwa rajungan dengan lebar karapas $\leq 10 \mathrm{~cm}$ belum sempat menemukan escape gap namun bubu sudah di angkat (hauled). Namun secara uji statistik penggunaan escape gap tidak berpengaruh terhadap lebar karapas dan berat hasil tangkapan. Hal ini diduga karena jumlah pengulangan yang sedikit sehingga sampel yang didapatkan juga sedikit.

\section{KESIMPULAN}

Dari hasil analisis data dan pembahasan didapatkan kesimpulan sebagai berikut:

1. Berdasarkan hasil analisis, didapatkan hasil terima $\mathrm{H} 1$, lebar dan panjang karapas rajungan memiliki hubungan linier positif yang kuat dengan nilai $\mathrm{R}^{2}=$ 0,8278 . Sedangkan lebar karapas dan tinggi tubuh rajungan memiliki hubungan linier positif yang kuat dengan nilai $\mathrm{R}^{2}=$ 0,6488 .

2. Desain escape gap yang paling sesuai digunakan adalah bentuk persegi yang terletak di bagian sisi bawah bubu dengan dimensi $4,6 * 2,6 \mathrm{~cm}$. 
3. Secara deskriptif, hasil tangkapan rajungan dengan lebar karapas $\leq 10 \mathrm{~cm}$ pada bubu dengan escape gap lebih rendah dari pada bubu tanpa escape gap. Sedangkan secara uji statistik menunjukkan terima $\mathrm{H} 0$, penggunaan escape gap pada bubu lipat tidak berpengaruh nyata terhadap lebar karapas dan berat hasil tangkapan rajungan (Portunus pelagicus).

\section{DAFTAR PUSTAKA}

[1] D. Setiyowati, "Kajian Stok Rajungan (Portunus pelagicus) Di Perairan Laut Jawa, Kabupaten Jepara," J. disprotek, vol. 7 , no. 1, 2016.

[2] L. Sara, W. H. Muskita, and O. Astuti, "Some population parameters of blue swimming crab (Portunus pelagicus) in Southeast Sulawesi waters, Indonesia.," Aquac. Aquarium, Conserv. Legis. J. Bioflux Soc. (AACL Bioflux), vol. 10, no. 3, 2017.

[3] A. Djunaedi, "Kelulushidupan dan Pertumbuhan Crablet Rajungan (Portunus pelagicus Linn.) pada Budidaya dengan Substrat Dasar yang Berbeda," ILMU Kelaut. Indones. J. Mar. Sci., vol. 14, no. 1, pp. 23-26, 2009.

[4] R. Kurnia and M. Boer, "Biologi Populasi Rajungan (Portunus Pelagicus) dan Karakteristik Lingkungan Habitat Esensialnya Sebagai Upaya Awal Perlindungan di Lampung Timur," J. Ilmu Pertan. Indones., vol. 19, no. 1, pp. 22-28, 2014.

[5] V. P. Ningrum, A. Ghofar, and C. Ain, "BEBERAPA ASPEK BIOLOGI PERIKANAN RAJUNGAN (Portunus pelagicus) DI PERAIRAN BETAHWALANG DAN SEKITARNYA Biological Aspects of Blue Swimmer Crab (Portunus pelagicus) in Betahwalang Waters and Around," SAINTEK Perikan. Indones. J. Fish. Sci. Technol., vol. 11, no. 1, pp. 62-71, 2015.

[6] F. P. T. Pangalila and I. L. Labaro, "Perbandingan Hasil Tangkapan Rajungan Pada Alat Tangkap Bubu Kerucut dengan Umpan yang Berbeda (The Comparison Catch of Swimming crab In Trap with Different Bait)," $J$. Ilmu dan Teknol. Perikan. Tangkap, vol. 2, no. 4, 2016.

[7] Kementerian Kelautan dan Perikanan, "Peraturan Menteri nomor 56/2016 tentang larangan penangkapan dan/atau pengeluaran lobster (Panulirus spp.), kepiting (Scylla spp.), dan rajungan (Portunus spp.) dari Wilayah Negara Republik Indonesia," Jakarta, 2016.

[8] D. Iskandar and R. Caesario, "PENGARUH POSISI UMPAN TERHADAP HASIL TANGKAPAN BUBU LIPAT," Bul. PSP, vol. 21, no. 1, pp. 1-9, 2013.

[9] C. Ummaiyah, A. D. P. Fitri, and B. B. Jayanto, "ANALISIS KERAMAHAN LINGKUNGAN BUBU RAJUNGAN MODIFIKASI CELAH PELOLOSAN DI PERAIRAN KABUPATEN REMBANG," J. Perikan. Tangkap Indones. J. Capture Fish., vol. 1, no. 03, 2017.

[10] D. I. Nugraheni, A. Fachrudin, Yonvitner, "Variasi Ukuran Lebar Karapas dan Kelimpahan Rajungan (Portunus pelagicus Linnaeus) di Perairan Kabupaten Pati," J. Ilmu dan Teknologi Kelautan Tropis., vol. 7, no. 02, pp. 493-510, 2015.

[11] A. Kurniasih, R. Irnawati, and A. Susanto, "The Escape Gap Effectiveness of Collapsible Trap to Catch Swimming Crab (Portunus 
pelagicus) in Banten Bay," J. Perikan. dan Kelaut., vol. 6, no. 2, pp. 95-103, 2016.

[12] M. Sudjana, "Metoda Statistika," Bandung: Tarsito, 2005.

[13] A. P. Dineshbabu, B. Sreedhara, and Y. Muniyappa, " Biology and exploitation of the blue swimmer crab, Portunus pelagicus (Linnaeus, 1758), from south Karnataka coast, India," Indian J. Fish., vol. 55, no. 3, pp. 215220, 2008.

[14] M. A. Rahman, F. Iranawati, E. S. Yulianto, and Sunardi, "Hubungan antar ukuran beberapa bagian tubuh rajungan (Portunus pelagicus) di Perairan Utara Lamongan, Jawa Timur," Journal of Fisheries and Marine Research, vol. 3, no 1, pp.111116, 2019.

[15] E. F. Prakosa, A. D. P. Fitri, and F. Kurohman, "ANALISIS CELAH PELOLOSAN PADA BUBU KUBAH TERHADAP HASIL TANGKAPAN RAJUNGAN (Portunus pelagicus) DI TPI DEMAAN KABUPATEN JEPARA," J. Fish. Resour. Util. Manag. Technol., vol. 6, no. 4, pp. 103-109, 2017.

[16] A. Boutson, C. Mahasawasde, S. Mahasawasde, S. Tunkijjanukij, and T. Arimoto, "Use of escape vents to improve size and species selectivity of collapsible pot for blue swimming crab Portunus pelagicus in Thailand," Fish. Sci., vol. 75, no. 1, p. 25, 2009. 